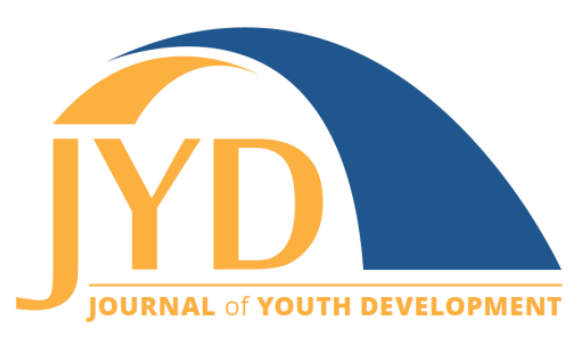

http://jyd. pitt. edu/ | Vol. 13 Issue 3 DOI 10.5195/jyd.2018.603 | ISSN 2325-4017 (online)

\title{
Restorative Youth Sports: An Applied Model for Resolving Conflicts and Building Positive Relationships
}

\author{
Michael A. Hemphill \\ University of North Carolina at Greensboro \\ hemphill@uncg.edu \\ Emily M. Janke \\ University of North Carolina at Greensboro \\ emjanke@uncg.edu
}

\section{Barrie Gordon}

Victoria University of Wellington

barrie.gordon@vuw.ac.nz

\section{Haley Farrar}

Victoria University of Wellington

haley.farrar@vuw.ac.nz

\begin{abstract}
When handled effectively, conflict provides opportunities to strengthen relationships and assist youth in developing peaceful conflict resolution skills. Sport participation is one context in which youth develop skills and encounter conflict. The purpose of this study was to develop an applied model that addresses conflict resolution in sport-based youth development programs. Using qualitative interviewing, a community-engaged approach guided the selection of participants and data analysis. We used the models of restorative practice and Teaching Personal and Social Responsibility (TPSR) through sports to guide our study. Following interviews with a variety of community partners, we found that the values of sport are often in conflict with restorative practices. However, a relational approach such as TPSR aligns well with the values of restorative practices. Based on our findings, an applied model was developed to illustrate how restorative practice can be utilized in a sport context. The Restorative Youth Sports (RYS) model recognizes that conflicts and tension are natural and inherent to all relationships. When handled appropriately, conflict provides opportunities to strengthen relationships. Youth sport provides a unique context where youth are presented with problems and conflicts to solve and promote healthy relationships among youth.
\end{abstract}

Key words: sport-based youth development, teaching responsibility, restorative practices, youth sports

(cc) $\mathbf{E Y}$ New articles in this journal are licensed under a Creative Commons Attribution 4.0 License. This journal is published by the University Library System, University of Pittsburgh and is cosponsored by the University of Pittsburgh Press. The Journal of Youth Development is the official peer-reviewed publication of the National Association of Extension 4-H Agents and the National AfterSchool Association. 


\section{Introduction}

Sport-based youth development (SBYD) refers to holistic and empowerment-based programs that prioritize the development of personal and social skills that are transferable to settings beyond sports (Holt et al., 2017). Adult leaders (e.g., coaches and teachers) play an important role in providing an appropriate context to foster positive development (Fraser-Thomas, Cote, \& Deakin, 2005). Further, sport participation has the potential to influence youth in a variety of settings including extended day programs (Hemphill \& Martinek, 2017), summer camps (e.g., Riley \& Anderson-Butcher, 2012), and school physical education programs (Hemphill, Templin, \& Wright, 2015). In the United States, approximately $71 \%$ of youth participate in sport while most others have opportunities to engage in school physical education courses or in afterschool physical activity programs (Farey \& Solomon, 2017). Therefore, the sport context can provide space for adult leaders to help youth to address key developmental assets, such as peaceful conflict resolution.

Holistic and empowerment-oriented programs, such as SBYD, focus on the strengths that youth possess, rather than their limitations. Missing from such programs, however, is the recognition of and specific strategies for helping youth to address tensions and conflicts that arise in their lives. This may be, in part, because conflict is seen as "bad" and is avoided when possible. Sometimes conflict is subtle, such as when we "stop and take notice that something is not right" (Lederach, 2003, p. 7), and other times it is more explicit. Feelings of tension or unease rise as individuals spend time interpreting the meaning of conflict and evaluating how their relationship to others is affected. For example, negative perceptions of conflict lead to conflict resolution strategies that separate those in conflict, relying on time and distance from the conflict to resolve it, rather than choosing a strategy that brings youth together to discuss their experiences and feelings for the purpose of rebuilding relationships.

Conflict transformation approaches focus on restoring and strengthening relationships constructively within a social context (Lederach, 2003). Everyone experiences varying types and levels of conflicts in interpersonal relationships, and each person has different responses and approaches to addressing them (Rahim, 1983). When handled effectively, conflict provides opportunities to strengthen relationships and assist youth in developing peaceful conflict resolution skills. Approaches vary in degree from assertiveness to aggressiveness, and according to personal experiences, preferences, and motivations, which makes the ability to address conflict effectively challenging (Volkema \& Bergmann, 1995). A complicated tapestry of personal characteristics, life experiences, and family backgrounds (Roloff, 2009; Siffert \& 


\section{The Restorative Youth Sports Model}

Schwarz, 2011) shape youth orientations toward conflict. By the time youth mature to adulthood, their approach has been relatively well established, which makes developing a repertoire of healthy and effective skills as a youth especially important for positive development (Benson \& Scales, 2009). Moreover, conflict resolution skills empower youth to establish and maintain positive relationships and enhance social and emotional health and wellbeing (Durlak, Weissberg, Dymnicki, Taylor, \& Schellinger, 2011).

The purpose of this study was to develop an applied model that addresses conflict resolution in SBYD programs. Prior to beginning the study, we selected two well-established frameworks to guide our study: restorative practices and Teaching Personal and Social Responsibility (TPSR) We chose to focus on restorative practices because they have been successfully adopted within a variety of contexts for youth, such as schools (Smith, Fisher, \& Frey, 2015) and juvenile courts (Zehr, 2002) in the United States and internationally. We identified the TPSR model as a commonly used approach to developing life skills through sport and physical education (Hellison, 2011). We chose TPSR because it is an approach to working with youth that has benefited from decades of applied practice and theory. Research on TPSR suggests it can have a positive impact on personal and social development of youth (Martinek \& Hellison, 2016), can provide tools to support coaches and teachers who implement the model (Hemphill et al., 2015), and can make connections to other youth development initiatives in schools (Escarti, Llopis-Goig, \& Wright, 2018). Together, restorative practices and TPSR serve as the basis for exploring the development of an applied model that addresses conflict resolution in SBYD programs. This article will present a review of literature on the two models we selected to guide our study, the methods for data collection and analysis, results, and a discussion of conclusions and practical implications.

\section{Review of Literature}

\section{Teaching Personal and Social Responsibility through Sports}

The TPSR model is an instructional model developed through fieldwork of Hellison (2011) and many colleagues (e.g., Martinek \& Hellison, 2009) who work in youth sport, physical activity, and physical education. The overarching goal of the model is to empower youth participants to be responsible in their conduct (personal responsibility) and in the way they treat others (social responsibility). TPSR programs provide strategies that encourage youth to transfer personal and social skills into other areas of their life. 


\section{The Restorative Youth Sports Model}

TPSR includes responsibility goals for youth participants, a structured lesson format, and responsibilities for the program leader. The goals for youth include respect for self and others, effort and participation, self-direction and goal setting, and leadership and caring and helping others. In addition to practicing responsibility within sports, the fifth and most important goal of TPSR is for youth to transfer skills or apply responsibility in other aspects of their life such as in school, in the community, or at home.

To integrate responsibility in lessons, a structured format is suggested. Program leaders are encouraged to take advantage of informal time before, during, and after lessons to develop relationships with youth. The lesson formally begins with an awareness talk to emphasize responsibility-based goals. The majority of TPSR lessons are devoted to physical activity time with responsibility integrated into the lesson. For example, a physical activity lesson focused on fostering leadership might require students to develop their own plan for an activity together with minimal direction from the program leader. This allows students to contribute as informal leaders. Youth leadership might be exhibited by leading the development of the strategy session, as well as teaching someone else a skill, or helping another youth solve a problem. The lesson format concludes with a group meeting to discuss and reflect on responsibility. Within each group meeting, program leaders ask students to reflect on their experiences together and share what they noticed or learned as it related to the day's responsibility goals. For example, what were some instances of leadership? Who showed leadership and what did that person do? How did that person's act of leadership affect the group? How might this type of leadership be transferred to school, home, or life outside of the program?

TPSR acknowledges that conflicts may occur and provides a variety of strategies to address them (Hellison, 2011). Teachers are encouraged to provide youth with self-officiating opportunities, which take advantage of the problem-solving opportunities inherent in sport participation. For students whose behavior is disruptive, TPSR encourages coaches to use a "sitting and talking bench" where players can discuss their frustrations before returning to play. According to Hellison (2011), students who experience conflict are asked to resolve their dispute and report that the problem is solved by "saying 'it's over"' (p. 280) before returning to play. An emphasis is also placed on setting expectations and reflective practice, both of which provide opportunities to peacefully resolve conflicts (Hellison, Martinek, \& Cutforth, 1996). TPSR has also been implemented with some success in contexts where conflict may occur, such as with gang-affiliated youth (Buckle \& Walsh, 2013). 


\section{The Restorative Youth Sports Model}

The TPSR model is increasingly the subject of empirical research and is used in a variety of international contexts (Martinek \& Hellison, 2016). Research suggests that the model can promote social and emotional learning when implemented with a high level of fidelity (Gordon, Jacobs, \& Wright, 2016). Practitioners and researchers have often made adaptations to the TPSR model to meet the needs of youth in their communities. For example, Walsh (2008) extended the model in combination with the theory of possible selves to help youth envision possible futures through a sport-based career club. Martinek (2016) developed a cross-aged teaching program to provide advanced leadership opportunities to youth. Other examples include integrating TPSR in classroom settings (Escarti et al., 2018) and a TPSR-based mentoring program (Martinek, Schilling, \& Johnson, 2001). Research suggests that the model can be applied across multiple contexts, but attention should be paid to the fidelity of implementation and the congruence of values between TPSR and the context in which it is implemented (Wright, Li, Ding, \& Pickering, 2010). Previous research suggests that differences in values can be an inhibitor to transferring life skills from TPSR values to contexts that do not espouse similar values (Lee \& Martinek, 2009). We found that although TPSR does have a presence in New Zealand, it has not been connected there to restorative practices (Gordon, 2010).

\section{Restorative Justice and Restorative Practices}

Restorative justice emerged from an understanding of crime as a violation of interpersonal relationships. It argues that those who suffer from wrongdoing should be able to have their needs addressed and those who commit wrongdoings should take responsibility for their actions (Zehr, 2002). In contrast with punitive criminal justice systems, restorative justice focuses on addressing harm rather than solely on the punishment of the offender. This is often implemented through practices such as a circle process where victims, offenders, and other parties participate in determining what accountability is needed and how to repair the harm that has been done. Using this harm-focused philosophy, restorative justice incorporates a variety of peaceful conflict resolution strategies.

Restorative practices are an extension of the restorative justice movement, which aims to help build and repair relationships. In line with many educators, we adopt the term restorative practices to account for the reactive strategies for addressing harm common to restorative justice as well as proactive relationship development strategies more common in education settings (Macready, 2009). In the context of schools, restorative practices have shown capacity to build social and emotional skills by focusing on relational practices that empower students to 
resolve conflicts (Morrison, Blood, \& Thorsborne, 2005). Using these practices has also led to meaningful reductions in suspension and referral rates in the contexts of urban schools. A review of research found that schools implementing restorative practices saw a decrease in office referrals and disruptive behaviors, which led to a reduction in school suspension rates (Lewis, 2009). From a student perspective, research reports that restorative practices facilitate positive relationships among teachers and students and can help reduce racial disparities in school discipline (Gregory, Clawson, Davis, \& Gerewitz, 2015). However, researchers emphasize that positive outcomes rely on proper implementation of restorative practice (Rofe, Stewart, \& Wood, 2016)

In the context of New Zealand schools, the Restorative Practice Model is explained by three related components (see Table 1). Each component explains practices and strategies used to facilitate relationship building and repairing harm.

\section{Table 1. Restorative Practice in Education Model}

\begin{tabular}{|l|l|}
\hline Model components & $\begin{array}{l}\text { Practices and strategies to facilitate relationship building and } \\
\text { repair harm }\end{array}$ \\
\hline Restorative essentials & $\begin{array}{r}\text { - Relational Approach } \\
\text { - Effective Communication } \\
\text { - Restorative Conversations }\end{array}$ \\
\hline Restorative circles & $\begin{array}{l}\text { - Community Building } \\
\text { - Dialogue } \\
\text { - Learning } \\
\text { - Decision Making } \\
\text { - Integration/Leaving } \\
\text { - Conflict/Healing }\end{array}$ \\
\hline Restorative conferences & - Mini Conferences \\
& - Classroom Conferences \\
& - Formal Restorative Conference \\
\hline
\end{tabular}

1. Restorative essentials focus on informal interactions that provide opportunities to develop relationships, communicate in a restorative manner, and have conversations to restore relationships. 


\section{The Restorative Youth Sports Model}

2. Restorative circles provide strategies to include all youth in conversations. The circles may include reactive approaches such as conflict/healing circles or relationship-building approaches such as integration circles to welcome new members to the community.

3. Restorative conferences provide formal processes to repair harm. The conferences aim to include students involved in an incident to explore what has happened, support taking accountability for the harm caused, and provide support to repair harm (New Zealand Ministry of Education, 2014).

Restorative practices are guided by a set of core values, including participation, respect, honesty, interconnectedness, accountability, and empowerment. Moreover, there is an expectation that teachers who facilitate restorative conversations promote an atmosphere of inclusiveness so that all voices can be heard (New Zealand Ministry of Justice, 2011). The core values provide a framework for building positive relationships, promoting personal responsibility, and providing just processes to repair harm done to relationships (Evans \& Vaandering, 2016). Importantly, restorative conferences follow a script to address three questions: (a) what happened, (b) who has been affected by it and how, and (c) what is needed to repair the harms and prevent reoccurrence? The script assures that restorative conferences focus on building, maintaining, and restoring relationships. The formal restorative conferences provide a mechanism to respond to harm, while restorative circles and essentials offer proactive strategies for developing positive relationships.

\section{Methods}

This study was conducted by a team of researchers and practitioners in Greensboro, North Carolina, and Wellington, New Zealand, each of whom has expertise in either restorative practices, TPSR, and/or community-engaged approaches to scholarship. Together, the expertise of these scholars forged a new and interdisciplinary perspective to address conflict in a SBYD setting. We adopted a community-engaged approach to our study, emphasizing and relying on community-university partnerships that are reciprocal, asset-based, and mutually beneficial (Saltmarsh, Hartley, \& Clayton, 2009). A primary goal for community-engaged approaches is to transform the participant relationship to a partner relationship, where and when possible. Partners in community-engaged scholarship are involved throughout the duration of the study, identifying the priorities to be addressed, the methods selected, collection of information and analysis of the findings, development and dissemination of products that come from the joint efforts, and review of the partnership. 


\section{The Restorative Youth Sports Model}

Reciprocity among partners is enacted through seeking, valuing, and respecting the knowledge, perspective, resources, and accountability that each partner brings to the work (Dostilio et al., 2012; Janke \& Clayton, 2011), though the type and extent of collaboration may vary across activities and partners depending on their resources and capacities (Jameson, Clayton, \& Jaeger, 2010). Mutual benefit ensures that partners understand how engagement in the collaborative work can help them to achieve their personal or organizational goals (Bringle, Clayton, \& Price, 2009). Following principles of community-engaged scholarship (see Community-Campus Partnerships for Health, 2006; Saltmarsh et al., 2009), our approach emphasized the positive and necessary abilities and commitments of individuals, communities, associations, and organizations to identify relevant issues; the importance of identifying and leveraging existing assets; and the importance of culturally appropriate, relational, and sustainable strategies to partnership and program development.

\section{Setting}

New Zealand is known worldwide for its commitment to restorative justice in communities and schools (Boyd \& Felgate, 2015), and Wellington, New Zealand has a large number of restorative justice practitioners and programs. Additionally, most youth in New Zealand (89\%) participate in community sports programs for at least 3 hours per week (Sport New Zealand, 2015). These conditions make Wellington an ideal context in which to involve youth sport providers and researchers in a community-engaged effort to examine best practices for the integration of restorative practices into SBYD programs.

By 2017, the New Zealand Ministry of Education (2014) reported that approximately 200 schools will meet the standard for "restorative schools" based on their comprehensive integration of restorative practice. These schools have established restorative approaches for addressing everyday violations such as tardiness, uniform violations, hurtful words spoken in the classroom, or disrespecting a teacher or staff member. Teachers and staff are provided with strategies for addressing the conflict in ways that help students to understand the impact of their behavior on the community, without also making them feel estranged as a result of their violation. As appropriate, restorative schools include victims of harm in the restorative process. An evaluation report suggests that restorative practices have been implemented effectively and that broader community connections through programs such as youth sport may improve outcomes (Boyd \& Felgate, 2015). 


\section{Participants}

To identify participants, the New Zealand co-authors provided names of individuals who administered either SBYD programs or restorative practice programs for youth. We used a snowball sampling method (Noy, 2008) once we began interviews, asking participants to recommend others who might be able to share ideas about the existence of and/or need for restorative practices in sport-based youth development programs

Participants ( $N=36 ; 21$ male, 15 female) had a variety of professional roles including university professors and researchers (6); physical educators and coaches of school, community, and elite sports programs (10); police officers (2); teachers and administrators at a restorative school (7); restorative justice practitioners (6); and youth development professionals (5). Several participants contributed multiple perspectives based on their diverse experiences. For example, a school administrator also had experience coaching youth sports. These participants came from a variety of organizational types including a university, a national sport organization, citywide sport associations, recreation councils run by a municipality, an afterschool program, and a restorative school. SBYD professionals coached soccer, basketball, rugby, and boxing, and used their experiences in these sports to inform their view of restorative practices in sport. The two Wellington-based authors of this study recommended initial participants based on their knowledge and experience related to our areas of interest. Those participants were then asked to recommend others who should be key contributors to this project. Hence, this study represents a nascent and emerging partnership of community and university practitioners and scholars seeking to understand how peaceful conflict resolution can be taught to youth through sport-based development programs.

\section{Data Collection}

The two lead authors met with participants in semi-structured interviews (Patton, 2002). Across 2 weeks, we convened focus groups ( $n=17$ participants; five focus group meetings) and met with individuals ( $n=19$ participants) as determined by the availability of participants. Following an asset-based strategy, our initial interview protocol asked questions related to (a) recommendations for what questions we should be asking to learn more about conflict, SBYD, and restorative practices; (b) understanding how participants define conflict; (c) what conflicts they see in their relevant work; (d) where they turn to for guidance when dealing with conflict in their relevant work; (e) how, if at all, they use restorative practices in their work; and (f) how they think this study could serve their goals for addressing conflict in sport-based youth development or related work. All interviews were audio recorded and transcribed verbatim. 


\section{Documents}

When possible, participants provided the research team with documents from their organization related to restorative practices, TPSR, or youth sports. Examples included a restorative practices handbook, a handbook on community youth sports, and other teaching tools related to restorative practices.

\section{Data Analysis}

We employed a collaborative qualitative analysis process (Richards \& Hemphill, 2018) to analyze interviews and documents. Our analysis was rooted in thematic data analysis and the constant comparative method (Patton, 2015). The two lead authors reviewed the data and created memos that discussed preliminary themes. The memoing process resulted in a qualitative codebook that was then used to analyze the entire data set. Two researchers who were not involved with the initial analysis then reviewed the findings to ensure they were reasonably derived from the data.

Ideally, community-engaged scholarship includes community partners in the data analysis phase. However, in practice, limitations in time and capacity limit the ability of communitybased professionals from participating in all phases of the study. Our goal was to ensure reciprocity and mutual benefit, as well as to encourage future partnerships with participants. Therefore, we asked participants in person as well as in follow up emails, how, if at all, they would like to continue to be involved and what they would like to see happen as a result of their involvement in a partnership that examines restorative practices in sport-based youth development. We learned that the majority of participants, at this point in the study, were interested in learning what the research team found through their conversations, and would be willing to provide feedback on the themes identified by researchers. None was interested in coding interviews for thematic analysis. Therefore, the academic research team chose to present the themes to community participants and potential partners by designing a website. Community partners were invited to share their feedback, increasing the trustworthiness of the researcher's findings. The authors have ensured that the results all reflect the broad range of perspective provided by participants in interviews and the general agreement provided by participants when presented with the results of this study. 


\section{Results}

Following analysis of all interviews and documents, we identified both the missed opportunity, and the potential for restorative practices to be integrated into SBYD programs as a way to teach peaceful conflict resolution. While restorative practices are not purposefully integrated into TPSR curriculum and practices, the two approaches share core values and a common focus on relationships, suggesting the potential for and benefit of joining the approaches together more intentionally and formally. Drawing from our findings, we present key components of an applied restorative youth sports model.

\section{Connections between Restorative Practices and TPSR}

Rarely do sport and physical education programs draw on restorative practices to address conflict. This finding held true even when the sport programs were situated within a restorative school. As described by participants, the current value structure of sport programs did not align well with restorative practice. However, discussions identified opportunities to extend restorative practices into a sports model by focusing on the relational aspects of sports and rethinking the meaning of conflict.

\section{Value (In)Congruence}

According to the school administrators, many school sport leaders' expectations are limited to helping youth develop sports skills and fitness in a fun and safe environment. This situation was complicated by the expectations of students and their families who often valued the opportunities for competition provided in sports. Given these challenges, the value congruence between a model such as TPSR and restorative practices may provide an opportunity to build a model that integrates restorative practices into youth sport and physical education programs.

Despite the potential for sport to be a "restorative model dream area," as one restorative school administrator called it, restorative practices have not found inroads into sports. One administrator who oversees school-wide implementation of restorative practice explained,

Sport is an interesting thing, isn't it? I [was the referee for] a football game. And on this side of the white line I'm a wellrespected teacher. Once you step over the line, you become a referee in soccer, we allow the kids to actually say lots of [inappropriate] things to the referee and it's a part of the game. 


\section{The Restorative Youth Sports Model}

The administrator provided insights into social norms in sports that were incompatible with restorative practices. For example, he explained that "I think the moral learning is all about perseverance and overcoming hardships ... I don't hear a lot of people talking about communication, empathy, or managing feelings of shame [in sport programs]." Other teachers provided several examples of different expectations family members have for sport participation, for example, "I've had a parent and coach who disagree on the values. The parent wants their son or daughter to have a bigger role...as a coach I value equal participation. "One experienced sport coach saw potential for restorative practice in sports, but cautioned that "the undercurrents within [sports] are anti-restorative in a lot of ways. "Several coaches echoed that sentiment, explaining that the value structure of sport programs would need to change so that "everything you do [is] in a restorative manner." Based on the perspectives of teachers, coaches, and administrators, many sports programs had a value structure that conflicts with and inhibits any attempt to integrate restorative practices. Therefore, a values-based framework may provide new opportunities for restorative practices in youth sports.

\section{Relationships at the Core}

Building positive relationships is at the core of TPSR and restorative practice. However, school administrators described sports as "not actually about building relationships or building skills that you can take into life, even though they mention those things." This perception seems to indicate a gap between sports and restorative practice in schools. The administrators explained that forging a connection between restorative practice and sports would require "saying that at the heart of everything we're doing is respectful relationships." One sport coach explained that restorative practice "might allow coaches to identify how these conflicts in relationships are present and how those relationships are therefore limited by our inability to recognize and address what that means for the team structure. "A restorative practice scholar explained that connections to school sports would help to "create a climate of restorative relationships right across a school." School-wide integration of restorative practices was described as a goal in documents and interviews, and restorative scholars recognized the sport and physical education areas as opportunities for growth.

Participants were asked to elaborate on the practical ways that restorative practices could be used in a sport setting. A consensus was found in the data that sport provides unique opportunities for building relationships that were not found in other school or community settings. For example, one sport coach with knowledge of restorative practice in schools explained that, 
The Restorative Youth Sports Model

The restorative model is that basically everyone makes mistakes, you know? . . to be human is to make mistakes, and players are making mistakes all the time in sports. So how do you actually handle that situation? You made a bad pass, how do we learn from that? . . . So, sport is the restorative model dream area, I think!

According to participants, mistakes and challenges are inherent to sport participation and those challenges represent issues that can be reflected upon through restorative practices, such as a circle process, and will result in better relationships among team members. Based on the perspectives of participants and a review of documents, restorative practices may be connected to sport programs by focusing on building positive relationships by proactively addressing conflicts and viewing the definition of conflicts broadly to include problems that naturally occur in the course of sport participation.

\section{Restorative Youth Sports Model}

Using TPSR as the framework for SBYD programs, and restorative practices as the framework for conflict transformation, we identified a new model to extend restorative practices into sport programs. Though we hope this model is broadly applicable, it should be noted that the model is grounded in an asset-based community development approach and in the perspectives of participants and institutions in Wellington, New Zealand. We relied on the TPSR model and restorative practices because both represent established frameworks used by coaches and teachers. The new applied model keeps the structure of TPSR intact while extending the model by explicitly focusing on building relationships and repairing harm. We arrived at the three areas based on our findings that the TPSR model and restorative practice include a set of core values, intentional strategies to facilitate relationship development, and processes to respond to conflict.

The model is informed by empirical data in three ways: (a) it reflects the findings of individual interviews and focus groups, (b) it draws upon practices identified in previous research and documents provided by restorative schools, and (c) it was agreed upon by participants through the member check process. The Restorative Youth Sports Model (see Table 2) has three important processes: 
- restorative sport practices,

- awareness circles, and

- team meetings.

Table 2. Restorative Youth Sports Model

\begin{tabular}{|c|c|}
\hline Model components & $\begin{array}{l}\text { Practices and strategies to facilitate relationship building and } \\
\text { repair harm }\end{array}$ \\
\hline $\begin{array}{l}\text { Restorative youth sports } \\
\text { essentials }\end{array}$ & $\begin{array}{l}\text { - } \text { Relational approach } \\
\text { - } \text { Effective communication } \\
\text { TPSR goals for youth/students } \\
\circ \text { Respect } \\
\circ \text { Effort } \\
\circ \text { Self-direction } \\
\circ \text { Leadership } \\
\circ \text { Transfer }\end{array}$ \\
\hline Awareness circles & $\begin{array}{l}\text { - } \text { Model respect } \\
\text { - } \text { Set expectations } \\
\text { - } \text { Provide youth voice } \\
\text { - } \\
\text { - } \text { Address conflict/healing } \\
\text { - Build relationships }\end{array}$ \\
\hline Team meetings & $\begin{array}{l}\text { - } \text { Address team strategy and planning } \\
\text { - } \text { Repair harm to relationships } \\
\text { - } \text { Address team priorities } \\
\text { - } \text { Provide youth leadership }\end{array}$ \\
\hline
\end{tabular}

\section{Restorative Sport Practices}

Restorative sport practices are the foundation to everything that happens in a restorative youth sport program. As one research participant stated, "everything you do should be in a restorative manner." To assist with this practice, the five goals of TPSR represent the types of behaviors one hopes to see youth exhibit through restorative youth sports. The fifth goal, transfer, emphasizes connections between the sport program and other areas such as community or school. Restorative essentials include a relational approach to programming. This approach 
suggests that adult leaders should seek opportunities to build relationships with youth and facilitate youth-building relationships with their peers.

\section{Awareness Circles}

Awareness circles provide a space to have restorative conversations and should occur routinely, at the beginning and end of practice or gameplay. The format can be similar to a sport huddle, but should have some essential practices and teaching strategies to ensure the integration of restorative practice. Awareness circles also provide problem-solving opportunities where youth participants can meet to problem solve and build relationships with their peers. When conflict and tensions occur, awareness circles aim to provide space to consider ways to repair the harm and prevent the situation from escalating.

\section{Team Meetings}

Team meetings provide a space for coaches and teachers to address conflict, tensions, or harm that occur through sport practice. This may also apply to problem solving through sports that focus on team strategies, practice plans, or game planning. The restorative script should guide this process to help youth and adults focus on identifying harm and restoring the team. Team meetings may function as mini-conferences that focus on the individual or individuals causing harm and those impacted by it.

\section{Strategies for Implementing the Model}

Participants in this study agreed that the Restorative Youth Sports Model has merit for integrating restorative practices into sports, particularly within the context of restorative schools. The model provides new strategies to address peaceful conflict resolutions. Participants argued, however, that it goes far beyond resolving conflicts, "the real power of restorative [practices] in improving [sport] is to improve the way it relates...we just redefine harm to focus on, 'what am I lacking and how am I not contributing the best I can?"' We propose extending restorative practices to help youth navigate problem-solving processes that naturally occur in sports such as developing team strategies, reflecting on mistakes, and preparing for competition.

Restorative youth sports prioritizes building healthy relationships among youth. Although we suggest some specific strategies, the model is based on the values of putting youth first, holistic 


\section{The Restorative Youth Sports Model}

development, and human decency. To enact such values, we borrow ideas from the TPSR model to suggest five principles:

1. Youth should be gradually empowered,

2. Restorative practices should be integrated into the sport experience.

3. Efforts should be made to transfer learning outside of sports.

4. Individuals are interconnected as members of a team and community.

5. Participants have accountability for individual actions and their impact on others.

\section{Implications and Conclusion}

Benson and Scales (2009) argue that positive relationships help youth develop valuable life skills such as peaceful conflict resolution. Moreover, relationships impact the well-being of youth by promoting personal and social skills to help navigate life experiences (Search Institute, 2018). Hence, Evans and Vaandering (2016) explain that nurturing healthy relationships is essential to providing youth with a positive learning environment. However, the abilities of youth to maintain healthy relationships should not be assumed. Our extension of restorative practices aims to recognize the centrality of relationships to the well-being of youth and provide intentional strategies to promote positive relationships through sports.

Given the centrality of relationships to both restorative practices and the TPSR model, we argue that TPSR provides the appropriate context to extend restorative practice into school sports while maintaining a focus on positive relationships. The TPSR model provides a central focus on relationships throughout the structured lesson format including opportunities for relational time, opportunities for reflection, and social interaction during physical activity time. Relationship development through youth programs seems to work best when positive experiences are embedded within the social norms of programs (Roehlkepartain et al., 2017). This approach is consistent with the research on both TPSR and restorative practice, where scholars have found that the values should be integrated throughout programming. The Restorative Youth Sports Model provides an opportunity for restorative schools to integrate their practices into sports in order to more fully realize the potential of holistic integration of restorative practices. As the participants in our study suggested, this model likely works best when adult program leaders share the values of the model. When those values do align, the model provides practice strategies for integrating restorative practices into daily practice routines (e.g., lesson plan format). More practical resources related to restorative practice and TPSR are widely available 


\section{The Restorative Youth Sports Model}

and could be used to support restorative youth sports. As one example, the TPSR model includes a reflection tool that has been used to assist teachers in implementing TPSR teaching strategies (Hemphill et al., 2015).

We refer to the Restorative Youth Sports Model as an applied model with the understanding that models are often a purposeful simplification of the constructs they describe. However, models do not need to be completely accurate or field tested to have value (Nilson, 2015). The Restorative Youth Sports Model serves as a descriptive tool to ensure appropriate representation of the values within restorative practices and TPSR and to support initial implementation of restorative practice in sport programs. Importantly, implementation of the model will elicit new questions for scholarship and practical challenges for practitioners. Consistent with our community-engaged approach, this model could provide new opportunities for community partners to inform the future directions of this work. Restorative youth sports is also consistent with reflective approaches to practice (Schon, 1987), as the model represents an initial examination of theory as it is described in the literature and used in practice.

There are several limitations to this study. Our data collection was limited to Wellington, New Zealand, and therefore should not be overgeneralized. To account for this limitation, the findings are grounded in two frameworks (TPSR and restorative practices) that are more broadly applied in a variety of contexts. Another important limitation is that our findings do not include the experiences and perspectives of youth participants. Given the emphasis on building relationships among youth, it is important to consider the youth perspective in future work related to this model.

Several challenges remain for the Restorative Youth Sports Model. The literature suggests that continuing professional development programs will be necessary to support the implementation of this model. Teachers and coaches may be supported through professional development workshops, opportunities to collaborate with their peers, and opportunities to reflect on their practices (Boyd \& Felgate, 2015; Hemphill et al., 2015). It is also important to recognize that this approach is not suitable for all youth sports programs. The applied model aims to enhance values-based programs that aspire to be inclusive of all youth, help youth develop relationships, and promote the development of personal and social skills within and beyond sports. Finally, specific attention is needed to understand the nature or tension, conflicts, and harms in sports and how restorative practices may enhance program leaders' ability to address those issues. Future practice and scholarships that addresses these challenges will make substantial contributions to the TPSR model and to restorative practice. 


\section{References}

Benson, P. L., \& Scales, P. C. (2009). Positive youth development and the prevention of youth aggression and violence. International Journal of Developmental Science, 3(3), 218-234. doi: 10. 3233/DEV2009-3302

Boyd, S., \& Felgate, R. (2015). A positive culture of support: Final report from the evaluation of PB4L school-wide. Wellington, New Zealand: Ministry of Education.

Bringle, R. G., Clayton, P. H., \& Price, M. F. (2009). Partnerships in service learning and civic engagement. Partnerships: A Journal of Service Learning \& Civic Engagement, 1(1), 1-20.

Buckle, M. E., \& Walsh, D. S. (2013). Teaching responsibility to gang-affiliated youths. Journal of Physical Education, Recreation \& Dance, 84(2), 53-58. doi: 10.1080/07303084.2013.757193

Community-Campus Partnerships for Health. (2006). Principles of good community-campus partnerships. Seattle, WA: Author.

Dostilio, L. D., Brackmann, S. M., Edwards, K. E., Harrison, B., Kliewer, B. W., \& Clayton, P. H. (2012). Reciprocity: Saying what we mean and meaning what we say. Michigan Journal of Community Service Learning, 19(1), 17-32. Retrieved from http://hdl.handle.net/2027/spo.3239521.0019.102

Durlak, J. A., Weissberg, R. P., Dymnicki, A. B., Taylor, R. D., \& Schellinger, K. B. (2011). The impact of enhancing students' social and emotional learning: A meta-analysis of school-based universal interventions. Child Development, 82(1), 405-432. doi: 10.1111/j.1467-8624.2010.01564

Escarti, A., Llopis-Goig, R., \& Wright, P. M. (2018). Assessing the implementation fidelity of a schoolbased teaching personal and social responsibility program in physical education and other subject areas. Journal of Teaching in Physical Education. doi: 10.1123/jtpe.2016-0200

Evans, K., \& Vaandering, D. (2016). The little book of restorative justice in education: Fostering responsibility, healing, and hope in schools. New York, NY: Good Books.

Farey, T., \& Solomon, J. (2017). State of play 2017: Trends and developments. Aspen, CO: The Aspen Institute.

Fraser-Thomas, J. L., Cote, J., \& Deakin, J. (2005). Youth sport programs: An avenue to foster positive youth development. Physical Education and Sport Pedagogy, 10(1), 19-40. doi:

$10.1080 / 1740898042000334890$

Gordon, B. (2010). An examination of the responsibility model in a New Zealand secondary school physical education program. Journal of Teaching in Physical Education, 29, 21-37. doi: 10.1123/jtpe/29.1.21

Gordon, B., Jacobs, J. M., \& Wright, P. M. (2016). Social and emotional learning through a teaching personal and social responsibility based after-school program for disengaged middle school boys. Journal of Teaching in Physical Education, 35, 358-369. doi: 10.1123/jtpe.2016-0106 
Gregory, A., Clawson, K., Davis, A., \& Gerewitz, J. (2015). The promise of restorative practices to transform teacher-student relationships and achieve equity in school discipline. Journal of Educational and Psychological Consultation, 25(1), 1-29. doi: 10.1080/10474412.2014.929950

Hellison, D. (2011). Teaching responsibility through physical activity. Champaign, IL: Human Kinetics.

Hellison, D., Martinek, T., \& Cutforth, N. (1996). Beyond violence prevention in inner-city physical activity programs. Peace and Conflict: Journal of Peace Psychology, 2(4), 321-337. doi: 10.1207/s15327949pac0204

Hemphill, M. A., \& Martinek, T. (2017). Community engagement through sport: University partnership to promote youth development. Kinesiology Review, 6, 311-316. doi: 10.1123/kr.2017-0027

Hemphill, M. A., Templin, T. J., \& Wright, P. M. (2015). Implementation and outcomes of a responsibilitybased continuing professional development protocol in physical education. Sport, Education, and Society, 20(3), 398-419. doi: 10.108013573322.2012

Holt, N. L., Neely, K. C., Slater, L. G., Camire, M., Cote, J., Fraser-Thomas, J., MacDonald, D., Strachan, L., \& Tamminen, K. A. (2017). A grounded theory of positive youth development through sport based on results from a qualitative meta-study. International Review of Sport and Exercise Psychology, 10(1), 1-49. doi: 10.1080/1750984X.2016.1180704

Jameson, J., Clayton, P., \& Jaeger, A. (2010). Community engaged scholarship as mutually transformative partnerships. In L. Harter, J. Hamel-Lambert, \& J. Millesen (Eds.), Participatory partnerships for social action and research (pp. 259-277). Dubuque, IA: Kendall Hunt.

Janke, E. M., \& Clayton, P. H. (2011). Excellence in community engagement and community-engaged scholarship: Advancing the discourse at UNCG (Vol. 1). Greensboro: University of North Carolina at Greensboro.

Lederach, J. P. (2003). The little book of conflict transformation. New York, NY: Good Books. Lee, O., \& Martinek, T. (2009). Navigating two cultures: An investigation of cultures of a responsibilitybased physical activity program and school. Research Quarterly for Exercise and Sport, 80(2), 230-240. doi: 10.1080/02701367.2009.10599557

Lewis, S. (2009). Improving school climate: Findings from schools implementing restorative practices. Bethlehem, PA: International Institute for Restorative Practices.

Macready, T. (2009). Learning social responsibility in schools: A restorative practice. Educational Psychology in Practice, 25(3), 211-220. doi: 10.1080/02667360903151767

Martinek, T. (2016). Project Effort: Creating responsible leadership through values-based learning. Active and Healthy Magazine, 23, 43-46.

Martinek, T., \& Hellison, D. (2009). Youth leadership in sport and physical education. New York, NY: Palgrave Macmillan.

Martinek, T., \& Hellison, D. (2016). Learning responsibility through physical activity. In N. L. Holt (Ed.), Positive youth development through sport ( $2^{\text {nd }}$ ed., pp. 180-190). New York, NY: Routledge. 
Martinek, T., Schilling, T., \& Johnson, D. (2001). Evaluation of a sport and mentoring program designed to foster personal and social responsibility in underserved youth. The Urban Review 33(1), 29-45. doi: $10.1023 / \mathrm{A}: 101033281$

Morrison, B., Blood, P., \& Thorsborne, M. (2005). Practicing restorative justice in school communities: The challenge of culture change. Public Organization Review, 5(4), 335-357. doi: 10.1007/s1115005-5095-6

New Zealand Ministry of Education. (2014). Positive behaviour for learning: Restorative practice kete. Wellington, New Zealand: Author.

New Zealand Ministry of Justice. (2011). Restorative justice: Best practices in New Zealand. Wellington, New Zealand: Author.

Nilson, P. (2015). Making sense of implementation theories, models, and frameworks. Implementation Science, 10(53). doi: 10.1186/s13012-015-0242-0

Noy, C. (2008). Sampling knowledge: The hermeneutics of snowball sampling in qualitative research. International Journal of Social Research Methodology, 11(4), 327-344. doi: 10.1080.13645570701401305

Patton, M. Q. (2002). Qualitative research and evaluation methods: Integrating theory and practice. Thousand Oaks, CA: Sage.

Rahim, M. A., (1983). A measure of styles of handling interpersonal conflict. Academy of Management Journal, 26(2), 368-376. doi: 10.2307/255985

Richards, K. A. R., \& Hemphill, M. A. (2018). A practical guide to collaborative qualitative data analysis. Journal of Teaching in Physical Education, 37(2), 225-231. doi: 10.1123/jtpe.2017-0084

Riley, A., \& Anderson-Butcher, D. (2012). Participation in a summer sport-based youth development program for disadvantaged youth: Getting the parent perspective. Children and Youth Services Review, 34(7), 1367-1377. doi: 10.1016/j.childyouth.2012.03.008

Roehlkepartain, E., Pekel, K., Syvertsen, A., Sethi, J., Sullivan, T., \& Scales, P. (2017). Relationships first: Creating connections that help youth people thrive. Minneapolis, MN: Search Institute.

Rofe, C., Stewart, M., \& Wood, M. (2016). Improving student's engagement: Changing classroom discourse using teacher restorative professional development. International Journal of Teaching and Case Studies, 7, 223-239. doi: 10.1504/IJTCS.2016.080933

Roloff, M. E. (2009). Links between conflict management research and practice. Journal of Applied Communication Research, 37(4), 339-348. doi: 1080/00909880903233200

Saltmarsh, J., Hartley, M., \& Clayton, P. (2009). Democratic engagement white paper. Boston, MA: New England Resource Center for Higher Education. Retrieved from https://repository.upenn.edu/gse_pubs/274

Search Institute. (2018). The developmental relationships framework. Minneapolis, MN: Author. 
Schon, D. A. (1987). Educating the reflective practitioner: Toward a new design for teaching and learning in the professions. San Francisco, CA: Jossey-Bass.

Siffert, A., \& Schwarz, B. (2011). Parental conflict resolution styles and children's adjustment: Children's appraisals and emotion regulation as mediators. The Journal of Genetic Psychology, 172(1), 2139. doi: 10. 1080/00221325.2010.503723

Smith, D., Fisher, D., \& Frey, N. (2015). Better than carrots or sticks: Restorative practices for positive classroom management. Alexandria, VA: Association for Supervision and Curriculum Development.

Sport New Zealand. (2015). Community sport: Strategy 2015-20. Wellington, New Zealand: Author.

Volkema, R. J., \& Bergmann, T. J. (1995). Conflict styles as indicators of behavioral patterns in interpersonal conflicts. The Journal of Social Psychology, 135(1), 5-15. doi:

10.1080/00224545.1995.9711395

Walsh, D. (2008). Helping youth in underserved communities envision possible futures. Research Quarterly for Exercise and Sport, 79(2), 209-221. doi: 10.1080/02701367.2008.10599484

Wright, P. M., Li, W., Ding, S., \& Pickering, M. (2010). Integrating a personal and social responsibility program into a wellness course for urban high school students: Assessing implementation and educational outcomes. Sport, Education, and Society, 15(3), 277-298. doi: $10.1080 / 13573322.2010 .493309$

Zehr, H. (2002). The little book of restorative justice. Intercourse, PA: Good Books. 